\title{
The Effect of Adrenaline on Insulin Releasing Polypeptide (IRP) Mediated Insulin Release in vivo in the Rat*
}

\author{
A. Shabaan, D.S. Turner, and V. Marks \\ Department of Biochemistry, University of Surrey, Guildford, Surrey, England \\ Received: February 2, 1974, and in revised form: July 8, 1974
}

Summary. Intestinal insulin releasing polypeptide (IRP) has been shown to potentiate the release of insulin in response to glucose both in vitro and in vivo in the rat. Adrenaline reduced the insulin secretory response to the intravenous infusion (I.V.) of glucose and to the infusion of glucose with IRP given either as a rapid injection or as constant infusion.

Key words: Adrenaline, IRP, intestinal hormones, insulin release, glucose infusion, secretin, glucose tolerance.
The nature of the mediator of intestinal augmentation of insulin secretion has aroused much speculation since the phenomenon was first described by McIntyre et al in 1964 [1]. Most of the well-known and characterised intestinal hormones have been proposed at

* The present study incorporates work accepted for the award of M.Sc. in Clinical Biochemistry to Ahmad A. Shabaan at the University of Surrey. some time or other but none satisfactorily fulfils the role of the intestinal mediator $[2,3]$. An intestinal insulin releasing polypeptide [IRP] which contains none of these hormones has recently been isolated and partially purified $[4,5]$. It has been shown to potentiate the release of insulin in response to glucose, both in vitro and in vivo, but to have no, or little effect in the absence of induced hyperglycaemia $[5,6]$.

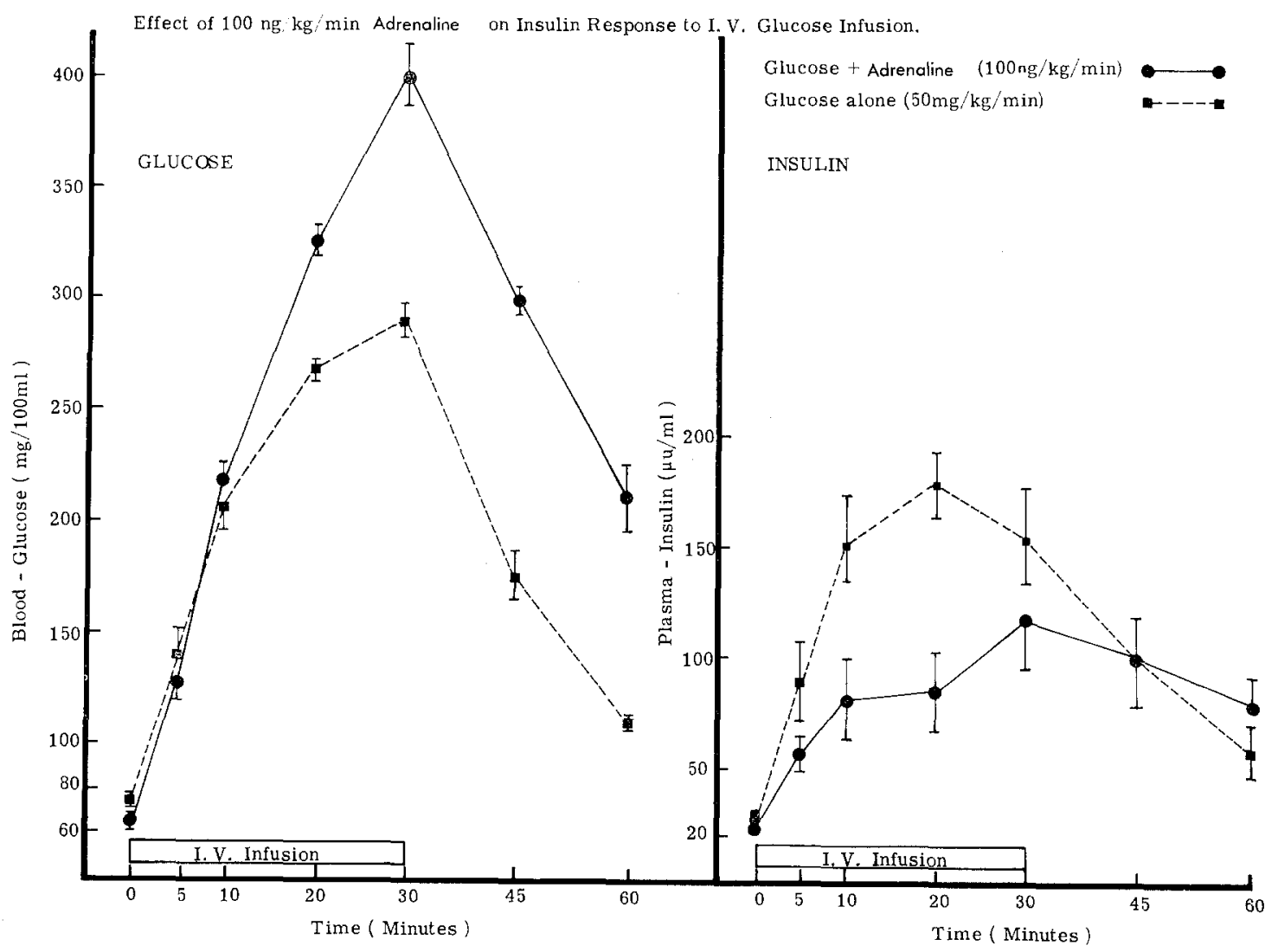

Fig. 1. Mean blood glucose and plasma insulin levels ( \pm S.E.M.) in two groups of six rats given either an I.V. infusion of glucose $(50 \mathrm{mg} / \mathrm{kg} / \mathrm{min})$ or glucose plus adrenaline $(100 \mathrm{ng} / \mathrm{kg} / \mathrm{min})$ 
The inhibitory effect of adrenaline and nor-adrenaline upon pancreatic insulin release provoked by intravenous glucose is well recognised [7,8]. Much less information is available about their effect upon oral glucose mediated insulin secretion. In a brief note Langs and Friedberg [9] reported that, in man, the I.V. infusion of adrenaline at a rate sufficient completely to suppress glucose stimulated insulin secretion, did not suppress the effect of oral glucose on insulin release. glucose plus IRP are reported and their possible relevance to the nature of the intestinal mediator discussed.

\section{Materials and Methods}

Overnight fasted Wistar rats aged 12 weeks, weighing $300-325 \mathrm{~g}$, were anaesthetised with Nembutal ${ }^{\circledR}$

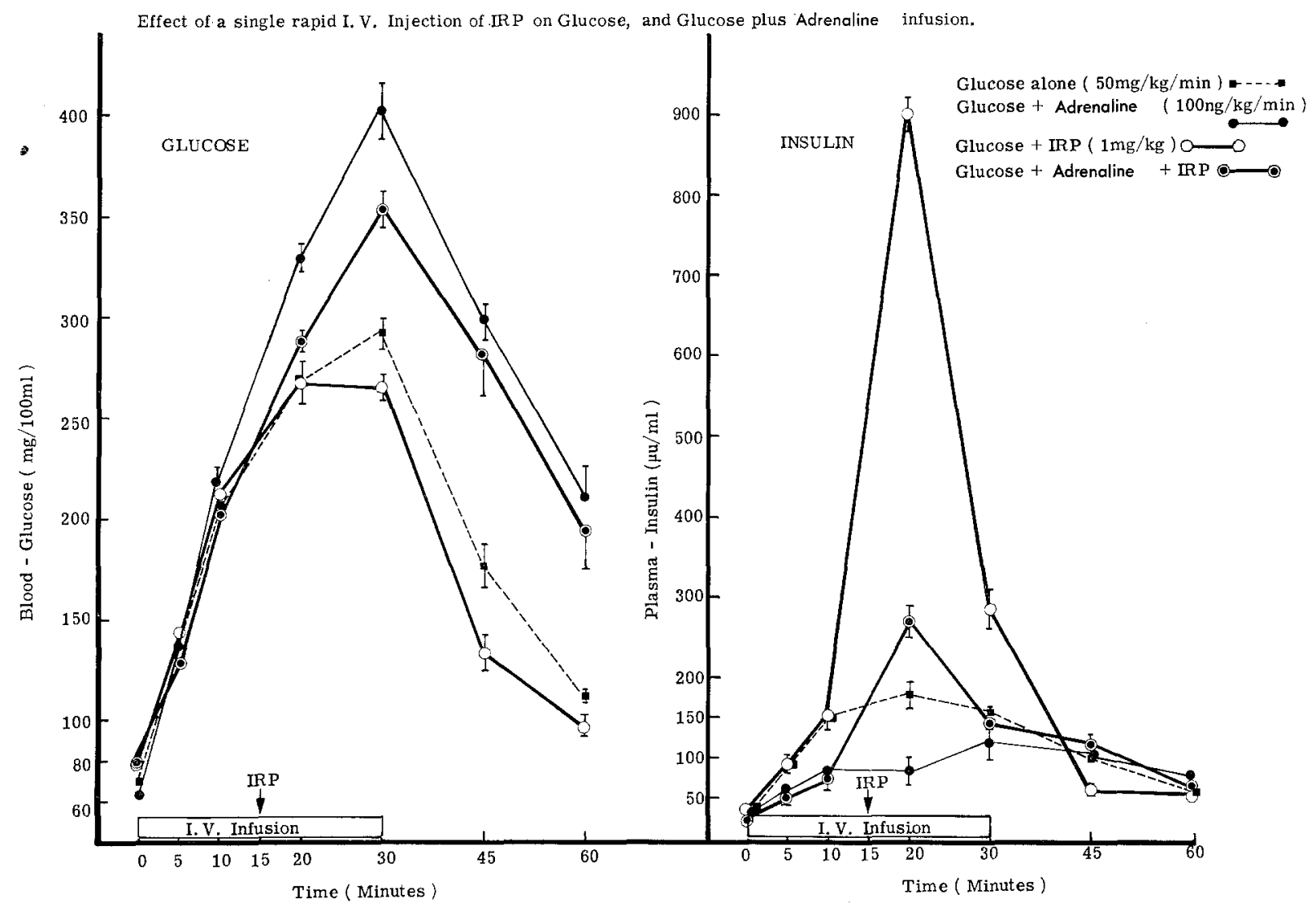

Fig. 2. Mean blood glucose and plasma insulin levels ( \pm S.F.M.) in four groups of Wistar rats given an intravenous glucose infusion $(50 \mathrm{mg} / \mathrm{kg} / \mathrm{min}$ ) over $30 \mathrm{~min}$

\begin{tabular}{lllll}
\hline $\begin{array}{l}\text { Group } \\
\text { No. }\end{array}$ & $\begin{array}{l}\text { No. of } \\
\text { Rats }\end{array}$ & $\begin{array}{l}\text { Glucose } \\
(50 \mathrm{mg} / \mathrm{kg} / \mathrm{min})\end{array}$ & $\begin{array}{l}\text { IRP (in saline) } \\
(1 \mathrm{mg} / \mathrm{kg})\end{array}$ & $\begin{array}{l}\text { Adrenaline } \\
(100 \mathrm{ng} / \mathrm{kg} / \mathrm{min})\end{array}$ \\
\hline 1 & 6 & + & - & - \\
2 & 6 & + & - & + \\
3 & 4 & + & + & + \\
4 & 4 & + & + & + \\
\hline
\end{tabular}

This was not confirmed [10]. Nelson et al [11] reported that adrenaline did not suppress secretin induced insulin release and on this basis suggested that in man secretin might be a suitable candidate for the hypothetical alimentary mediator.

In the present paper the results of studies in the rat concerning the effect of adrenaline on the insulin response to the intravenous infusion of glucose and of
(40 $\mathrm{mg} / \mathrm{kg}$ body weight, I.P.). IRP, prepared as previously described [5] was dissolved in saline or, together with adrenaline (B.P. MacCarthys), either in $7 \%$ or $14 \% \mathrm{w} / \mathrm{v}$ glucose solution, containing ascorbic acid $(2 \mathrm{mg} / \mathrm{ml})$ as adrenaline preservative. The constant infusion of approximately $0.1 \mathrm{ml} / \mathrm{min}$ for $30 \mathrm{~min}$ of the glucose or glucose plus adrenaline solutions was given into a femoral vein using a syringe pump. The exact 
protocol followed in each experiment is given in the results section.

Blood for glucose and plasma insulin measurements was obtained at regular intervals from the tail vein. Blood glucose was measured on the Autoanalyzer (Technicon Ltd) using an automated glucose oxidase method (Boehringer). Plasma insulin was determined by a double antibody radioimmunoassay procedure [12] using human insulin as standard.
The effect of adrenaline on insulin release after a rapid injection of IRP dissolved in saline was studied 15 min after the start of an infusion of either glucose or glucose plus adrenaline. The results, shown in Fig. 2 , indicate that insulin release following rapid intravenous injection of IRP was markedly, but not completely, inhibited by adrenaline $(p<0.001)$. The effect of adrenaline on insulin release provoked by a continous infusion of IRP is shown in Fig. 3. In this experi-

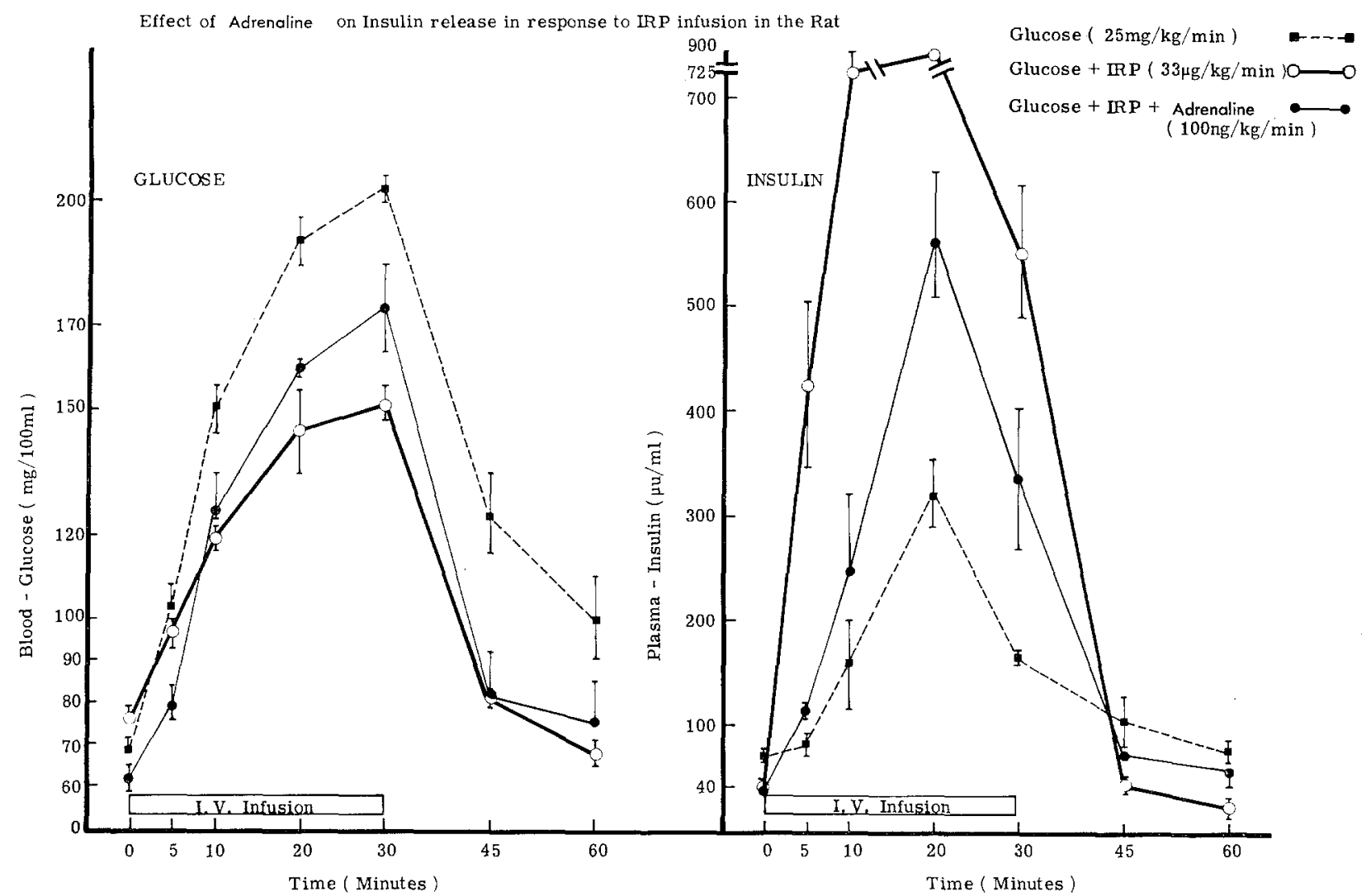

Fig. 3. Mean blood glucose and plasma insulin levels ( \pm S.E.M.) in three groups of four rats. The first (control) group was given an I.V. glucose infusion $(25 \mathrm{mg} / \mathrm{kg} / \mathrm{min}$ ) for $30 \mathrm{~min}$ and the second was given glucose plus adrenaline $(100 \mathrm{ng} / \mathrm{kg} / \mathrm{min})$. The third group received IRP $(33 \mu \mathrm{g} / \mathrm{kg} / \mathrm{min})$ in addition to glucose and adrenaline

\section{Results}

Preliminary experiments were carried out to find the smallest dose of adrenaline to suppress insulin secretion in response to I.V. glucose infusions in the rat. These experiments showed that adrenaline in doses within the range $10-60 \mathrm{ng} / \mathrm{kg} / \mathrm{min}$, which had previously been reported as effective in man, [8] did not cause significant inhibition of insulin release in the rat. Adrenaline at a dose level of $100 \mathrm{ng} / \mathrm{kg} / \mathrm{min}$ inhibited insulin release at all time intervals (Fig. 1), despite blood glucose levels much higher than in animals receiving glucose alone. This dose of adrenaline was used in all subsequent experiments. ment glucose was infused at a lower rate than in previous experiments, which accounts for the lower blood glucose levels throughout. The marked and sustained elevation of plasma insulin produced by IRP plus glucose, compared with that produced by glucose alone, was significantly attenuated, but not abolished, by adrenaline at all time intervals during the infusions $(p<0.001$ at $20 \mathrm{~min})$.

\section{Discussion}

The dose of adrenaline found in the present study to be effective as an inhibitor of insulin secretion in re- 
sponse to intravenous (I.V.) glucose infusions in rats was larger than that reported by Cerasi et al. [8] to be effective in humans, but similar to that actually used in man by most previous investigators $[7,9,10,12,13]$.

It is clear from the experiments described that adrenaline markedly inhibits the potentiating effect of IRP upon glucose-stimulated insulin secretion in the rat. Whether this is evidence for or against its merits as a candidate for the role of alimentary mediator of insulin release is uncertain. In contrast to the plethora of studies demonstrating inhibition by catecholamines of glucose mediated insulin release in vivo and in vitro, both in animals and in man, the only studies of their effect upon alimentary mediated insulin release known to us are those of Langs and Friedberg [9] and Fallucca et al. [10]. The latter showed, in three post-gastrectomy patients, a substantial and highly significant, though incomplete, inhibition by adrenaline of the exaggerated insulinaemic response to oral versus intravenous glucose.

IRP would seem, therefore, to qualify for further consideration as an intestinal mediator of glucose stimulated hyperinsulinaemia.

Acknowledgements. Thanks are due to the British Diabetic Association and Wellcome Foundation, Beckenham, for generous support.

\section{References}

1. McIntyre, N., Holdsworth, C.D., Turner, D.S.: New interpretation of oral glucose tolerance. Lancet 1964 II, $20-21$

2. Turner, D. S.: Intestinal hormones and insulin release: In vitro studies using rabbit pancreas. Horm. Metab. Res. 1, 168-174 (1969)
3. Marks, V., Samols, E.: Intestinal factors in the regulation of insulin secretion. In: Advances in metabolic disorders, pp. 1-38, (Ed. Levine, R., Luft, R.) New York: Academic Press 1970

4. Turner, D.S.: Intestinal factors and the control of insulin release. University of London: Ph.D. Thesis 1972

5. Turner, D.S., Shabaan, A., Etheridge, L., Marks, V.: The effect of an intestinal polypeptide fraction on insulin release in the rat in vitro and in vivo. Endocrino$\log y 93,1323-1328(1973)$

6. Turner, D.S., Marks, V.: Enhancement of glucosestimulated insulin release by an intestinal polypeptide in rats. Lancet $\mathbf{1 9 7 2} \mathrm{I}, 1095-1097$

7. Porte, D., Graber, A.L., Kozuya, T., Williams, R.H.: The effect of epinephrine on immunoreactive insulin levels in man. J. clin. Invest. 45, 228-236 (1966)

8. Cerasi, E., Luft, R., Effendic, S.: Antagonism between glucose and epinephrine regarding insulin secretion: a dose response study in man. Acta med. scand. 190, 411-417 (1971)

9. Langs, H.M., Friedberg, D.: Effectiveness of glucose administration orally in overcoming the epinephrine block of insulin. Clin. Res. 14, 283 (1966)

10. Fallucca, F., Javicoli, M., Tamburrano, G., Menzinger, G., Andreani, D.: Effect of epinephrine on insulin, glucagon and growth hormone in gastrectomised patients during glucose administration. Acta diabet. lat. 8. $1111-1128$ (1971)

11. Nelson, J.K., Rabinowitz, D., Merimee, T.J.: Effect of epinephrine on insulin release in man induced by secretin. Nature 215, 883 - 884 (1967)

12. Samols, E., Bilkus, D.: A comparison of insulin immunoassays. Proc. Soc. exp. Biol. (N.Y.) 115, $79-84$ (1964)

13. Blackard, W.G.: Suppression of plasma immunoreactive insulin by epinephrine in obese subjects. Proc. Soc. exp. Biol. (N.Y.) 126, $788-791$ (1967)

Dr. Vincent Marks

Dept. of Biochemistry

St. Luke's Hospital

Univ of Surrey

Guildford, Surrey GU2 5XH

England 